\title{
Emergence of a Novel Virus - A Review Article
}

\section{RJ Charulatha ${ }^{1}$, B Krishna Prasanth ${ }^{2 *}$ and Hariharan $\mathbf{S}^{\mathbf{3}}$}

${ }^{1}$ Second Year Post Graduate, Department of Community Medicine, Sree Balaji

Medical College and Hospital, India

${ }^{2}$ Epidemiologist and Assistant Professor, Department of Community Medicine, Sree

Balaji Medical College and Hospital, India

${ }^{3}$ Assistant Professor, Department of Community Medicine, Sree Balaji Medical

College and Hospital, India

*Corresponding Author: B Krishna Prasanth, Second Year Post Graduate,

Department of Community Medicine, Sree Balaji Medical College and Hospital, India.

DOI: $10.31080 /$ ASMI.2020.04.0769
Received: October 17,2020

Published: January 28, 2021

(C) All rights are reserved by , B Krishna

Prasanth., et al.

\section{Abstract}

The commencement of the $21^{\text {st }}$ century has witnessed deadly viral infections mainly SARS-CoV and MERS-CoV in 2002 and 2012 subsequently. The current decade further ascended with the emergence of the first outbreak of pneumonia of unknown origin from Wuhan City, China which was later identified exclusively as the epicenter of the disease and later linked to the spread of the disease resulting in pandemic [1]. Genomic analysis revealed that SARS-CoV-2 is phylogenetically related to severe acute respiratory syndrome-like (SARS-like) bat viruses, therefore bats could be the possible primary reservoir. The intermediate source of origin and transfer to humans is not known, however, the rapid human to human transfer has been confirmed widely. There is no clinically approved antiviral drug or vaccine available to be used against COVID-19. However, few broad-spectrum antiviral drugs have been evaluated against COVID-19 in clinical trials, resulted in clinical recovery. In the current review, we summarize and comparatively analyze the emergence and pathogenicity of COVID-19 infection and previous human coronaviruses severe acute respiratory syndrome coronavirus (SARS-CoV) and middle east respiratory syndrome coronavirus (MERS-CoV). This article gives a brief view about this new virus [2]. Since knowledge about this virus is rapidly evolving and under research, readers are urged to upgrade themselves regularly [3].

Keywords: SARS-CoV-2; COVID-19; MERS-CoV

\section{Introduction}

The name "Coronavirus" was coined from the word "corona" that is, a crown depicting its crown-like morphology as seen under the electron microscope in 1968. Coronavirus is spherical; single stranded, enveloped RNA viruses from 60 to $140 \mathrm{~nm}$ in diameter and covered with club shaped glycoprotein when observed in electron microscope. According to the International Committee on Taxonomy of Viruses, coronavirus is belonging to order Nidovirales, family Coronaviridae, and subfamily Coronavirinae. Based on serological evidences, coronavirinae is divided into four genera: Alphacoronavirus $(\alpha)$, betacoronavirus $(\beta)$, gammacoronavirus $(\Upsilon)$, and deltacoronavirus $(\delta)$. Some of them were affected human and causes respiratory infection as well as other affected to animal such as cats, mice, pigs, and dog.

This decades first corona virus that emerged on exposure to the Huanan seafood wholesale market in Wuhan City, Hubei province of China with a population of over 11 million people was named as 


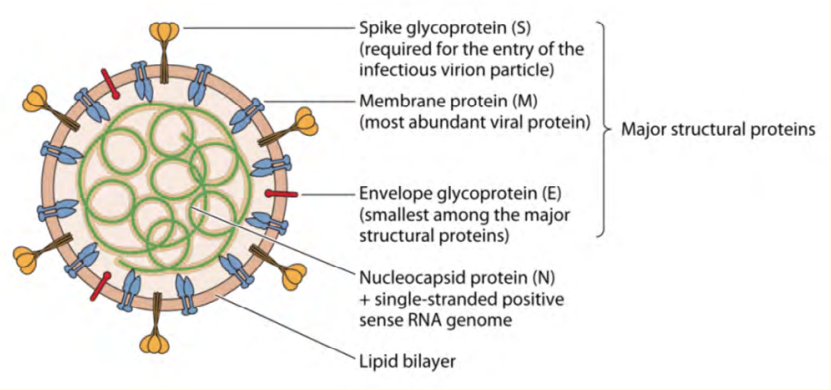

Figure 1
SARS-CoV 2 or 2019 - nCoV and the disease it caused was named as Severe Specific Contagious Pneumonia (SSCP) [1]. The novel corona virus 2019-nCoV is an enveloped RNA virus that belongs to a member of genus Betacoronavirinae, subgenus Sarbecovirus of Orthocoronavirinae sub family, ranging from $60 \mathrm{~nm}$ to $140 \mathrm{~nm}$ in diameter with spikes like projections of glycoproteins on its surface and is entirely different from the viruses that caused SARS and MERS [4].

There have been two events in the past two decades wherein crossover of animal betacorona viruses to humans has resulted in severe disease. The first such instance was in 2002- 2003 when a new coronavirus of the $\beta$ genera and with origin in bats crossed over to humans via the intermediary host of palm civet cats in the Guangdong province of China, named as Severe Acute Respiratory Syndrome (SARS) that nearly affected 8422 people, mostly in China and Hong Kong and caused 916 deaths (mortality rate 11\%) before being contained. Almost a decade later, in 2012, Middle East Respiratory Syndrome (MERS) also of bat origin, emerged in Saudi Arabia with dromedery Camels as the intermediate hosts and affected 2494 people and 858 deaths (mortality rate 34\%) [2]. To assess the magnitude of the risk posed by these novel virus, there are three parameters to be understood : (I) transmission rate that denotes the number of newly infected people from a single case (II) case fatality rate which is the percentage of cases that results in death and (III) to determine whether asymptomatic transmission is possible. As per WHO, current estimates of 2019-nCoV case fatality rate suggest that it is less deadly than the previous corona viruses, but the infection seems to spread at a rapid rate more easily. Rate of reproduction of 2019-nCoV ranges 2 to $2.5 \%$ [5].
Epidemiology

In December 2019, China reported a number of pneumonia cases of unknown etiology. The surveillance system was activated and respiratory samples of patients were sent to reference lab for etiologic investigation. On December $31^{\text {st }} 2019$, China informed WHO about the onset of deadly pneumonia illness. On January 9, WHO issued a statement saying that Chinese researchers have made a "preliminary determination" of the virus as a novel Corona virus [6] that had $>95 \%$ homology with the bat virus and $>70 \%$ similarity with SARS-CoV. In a meeting on January 30 , as per the International Health Regulation (IHR), the outbreak was declared as Public Health Emergency of International Concern (PHEIC) as it had spread to 18 countries with four countries reporting human to human transmission [7]. On February 11, WHO announced a name for the new coronavirus disease as COVID-19. An additional landmark occurred on February 26, as the first case of the disease not imported from China, was recorded in United States [7]. On March 11 , its status was amended to pandemic. On $20^{\text {th }}$ April, the virus spread had been recorded in almost 210 countries and territories around the world and 2 International conveyance.

As on September $28^{\text {th }}$, a total of $33,361,560$ cases has been reported. Almost 76,24,690 (99\%) are considered as mild cases and $65,071(1 \%)$ are critically ill. About 25,671,799 cases had an outcome. 24,668,608 (96\%) people had recovered and 10,03,191 (4\%) deaths had been recorded globally. In present scenario, USA has recorded most number of cases $(72,87,561)$ worldwide [5]. In India, the first case of COVID -19 was reported on January 30, in Kerala, which soon turned into 3 cases on February $3^{\text {rd }}$, all were students who had returned from Wuhan, China. As on September $28^{\text {th }}$, The Ministry of Health and Family Welfare in India has confirmed a total of $60,83,888$ cases, 9,67,381 (15.81\%) active cases; $50,20,881$ (82.58\%) recovered and 95,626 (1.57\%) deaths. Maharashtra bears maximum number of cases $(13,39,232$ case) followed by Andhra Pradesh $(6,75,674$ cases $)$ and Tamilnadu being the third leading state with a total of 5,80,808 cases (46,341 active, 9313 deaths and 5,25,154 recovered). The first case in Tamilnadu was a 45 year old male from Kancheepuram, who returned from Oman to Chennai airport on $28^{\text {th }}$ February, 2020. He was tested positive for COVID-19 on $7^{\text {th }}$ March.

\section{Clinical manifestations}

COVID-19 typically causes flu-like symptoms including a fever and cough. Middle aged and elderly patients with underlying 
chronic diseases were found to be more susceptible to respiratory failure and thereby have poor prognosis. Disease in pregnant women, neonates, infants and children were also reported, but significantly in milder form than their adult counterparts [3]. Male predisposition (76\%) of the disease had been observed. Person to person transmission occurs primarily via direct contact or through droplets spread by coughing or sneezing from an infected individual [8].

The symptoms of COVID-19 infection appears during an incubation period that ranges from 4 to 14 days, with a median of approximately 5.2 days. This period depends on the age of the patient and status of the patient's immune system [8]. The most common symptoms at illness onset are fever (99\%), fatigue (70\%), dry cough (60\%), myalgia (44\%) and dyspnoea (26\%). Less common symptoms are headache, dizziness, diarrhoea, nausea and vomiting 47. Symptoms such as pharyngeal pain, dyspnoea, dizziness, abdominal pain and anorexia are more likely to be present in patients with severe illnesses 27 . In addition, patients who are elderly, have underlying co-morbidities including hypertension, diabetes, cardiovascular disease and cerebrovascular disease are more likely to have adverse outcomes [9]. The most common complication of COVID-19 are Acute Respiratory Distress Syndrome (ARDS) which is due to occurrence of cytokine storm that results in exaggerated immune response, immune regulatory network balance and finally to multi organ failure.

\section{Pathogenesis}

The pathophysiology of unusually high pathogenicity for SARSCoV or MERS-CoV has not been completely understood. Early studies have shown that increased amounts of proinflammatory cytokines in serum (eg, IL1B, IL6, IL12, IFN $\gamma$, IP10, and MCP1) were associated with pulmonary inflammation and extensive lung damage in SARS patients. 22 MERS-CoV infection was also reported to induce increased concentrations of proinflammatory cytokines (IFN $\gamma, \mathrm{TNF} \alpha$, IL15, and IL17). 23 We noted that patients infected with 2019-nCoV also had high amounts of IL1B, IFN $\gamma$, IP10, and MCP1, probably leading to activated T-helper-1 (Th1) cell re sponses. Moreover, patients requiring ICU admission had higher concentrations of GCSF, IP10, MCP1, MIP1A, and TNF $\alpha$ than did those not requiring ICU admission, suggesting that the cytokine storm was associated with disease severity. However, 2019-nCoV infection also initiated increased secretion of T-helper-2 (Th2) cy- tokines (eg, IL4 and IL10) that suppress inflammation, which differs from SARS-CoV infection. 22 Further studies are necessary to characterise the Th1 and Th2 responses in 2019-nCoV infection and to elucidate the pathogenesis. Autopsy or biopsy studies would be the key to understand the disease [10].

\section{Investigations and treatment}

The most common laboratory abnormalities among patients hospitalized with COVID-19 are marked lymphopenia, prolonged prothrombin time, elevated lactate dehydrogenase, $\mathrm{C}$ reactive protein, and elevated D-dimer. These laboratory abnormalities are similar to the ones seen in SARS-CoV and MERS-CoV infections [9]. A CXR of an affected individual shows bilateral infiltrations. Multiple, patchy, sub-segmental or segmental ground-glass density shadows classified as "paving stone-like" changes by fine-grid or small honeycomb-like thickening of interlobular septa seen on CT chest [11]. A throat or nasopharyngeal swab tested for reverse transcriptase polymerase chain reaction (RT-PCR) to detect SARS - CoV 2. ICMR has recommended the use of rapid antibody testing for coronavirus diagnosis in high containment zone on April $2^{\text {nd }}$.

At present treatment involves essential supportive and symptomatic measures as there are no specific antiviral drugs or vaccines against covid-19 for potential therapy of humans. The only option available are broad spectrum antiviral drugs like nucleoside analogue or HIV protease inhibitor that could attenuate viral infection or hydroxychloroquine phosphate or interferons or intravenous Immunoglobulin, until the specific drug of choice becomes available [8]. Other measures includes Renal replacement therapy or plasma infusion of patients recovered from COVID-19. In hypoxic patients, provision of oxygen through nasal prongs, High Flow Nasal Cannula (HFNC), non invasive ventilation were indicated. In some cases, mechanical ventilation or Extra Corporeal Membrane Oxygenation (ECMO) support were needed.

During the SARS outbreak in 2003, corticosteroid therapy was used to reduce inflammatory-induced lung injury. In Covid-19, too, many countries are investigating the effectiveness of corticosteroid therapy on patients with an acute respiratory infection. Also, the World Health Organization (WHO) has prioritised the evaluation of corticosteroids in clinical trials to assess safety and efficacy. In interim guidelines on Covid-19 treatment released on May 27, the WHO has recommended "against the routine of systematic corticosteroid" for treatment of viral pneumonia. It said a systematic 
review and meta-analysis of the impact of corticosteroid therapy on persons with SARS-CoV-2, SARS-CoV and MERS-CoV revealed corticosteroids did not significantly reduce the risk of death, did not reduce hospitalisation duration, ICU admission rate and/or use of mechanical ventilation, and had several adverse effects [12].

Favipiravir is an anti-viral drug and it is approved in Japan for treating influenza. It is currently being tested in 18 clinical trials for Covid-19 and results from two studies have shown a positive outcome, while data from other trials is awaited [13].

\section{Prevention}

To reduce the risk of transmission in the community, Health promotion - non pharmacological interventions such as individuals advised to maintain good hydration and nutrition, to follow frequent hand wash with a sanitizer or soap and water, avoid touching their face often and to maintain social distancing by avoiding close contact (1meter or 3 feet) with people who are unwell, to avoid unnecessary, non - essential travel to places with ongoing transmission and to practice respiratory hygiene by using elbows while sneezing or coughing and to wear face mask. Disaster mitigation such as isolation of the suspected individuals in hospital or anyone who had contact but shows no symptoms at their home, setup of more hospitals with multi infrastructure required to deal with infected cases, a clear direct public awareness campaign and lock down of public were followed. Use of Personal Protective Equipments (PPE) by health care providers also play a major role in prevention.

Severe years after the global epidemic of SARS-CoV and MERSCoV,the current SARS-CoV 2/2019-nCoV outbreak serves as a reminder of how novel pathogens can rapidly emerge and spread through the human population, which may eventually cause severe public health crisis [9]. Similar to previous outbreaks, the current scenario which was indeed expected will be contained and end in apparent triumph in the near future under the collective effort of virologists, medical professionals, pharmacology and epidemiology researchers along with political and public support that works globally in network mode [14].

However the real question is how are we planning to counter the next zoonotic disease which may occur within next 5 to 10 years or even within a lesser span of time. Extensive researches on such viruses are typically conducted only when they result in specific disease outbreak as they are not isolated and studied prior to the outbreak [8]. More focus on screening, identification, isolation and follow-up of cases should be cultivated. Designing antiviral drugs and vaccines against several other emerging diseases in advance will help in development of suitable therapeutic agents against the same, but until then we must rely exclusively on various control and preventive measures to prevent these virus spread from becoming epidemic or pandemic [15].

\section{Conclusion}

This new virus outbreak has challenged the economic, medical and public health infrastructure of a country. More so, future outbreaks of various viruses and pathogens of zoonotic origin are likely to be expected. Therefore apart from curbing this outbreak, efforts should be made to device comprehensive measures to prevent and control further outbreaks [5].

With this emerging battle against this deadly virus, the WHO has strategized to interrupt human-human contact, isolate patients at early stages, identify and reduce transmission from the animal source, address crucial mysteries about the virus and accelerate research, communicate information correctly to the public and minimize the social and economic impact [16].

\section{Financial Support}

None.

\section{Declaration of Competing Interest}

None.

\section{Acknowledgement}

None.

\section{Bibliography}

1. Malik YS., et al. "Emerging novel coronavirus (2019-nCoV)current scenario, evolutionary perspective based on genome analysis and recent developments". Veterinary Quarterly 40.1 (2020): 68-76.

2. Shereen MA., et al. "COVID-19 infection: Origin, transmission, and characteristics of human coronaviruses". Journal of Advanced Research 24 (2020): 91-98.

3. H Singhal T. "A Review of Coronavirus Disease-2019 (COVID-19)". The Indian Journal of Pediatrics 13 (2020): 1-6. 
4. Zhu N., et al. "A novel coronavirus from patients with pneumonia in China, 2019". New England Journal of Medicine 382.8 (2020): 727-733.

5. https://www.worldometers.info/coronavirus/

6. https://www.thehindu.com/sci-tech/science/all-about-thechina-coronavirus-covid-19/article30692734.ece

7. Cascella M., et al. "Features, evaluation and treatment coronavirus (COVID-19)”. InStatPearls (2020).

8. Rothan HA and Byrareddy SN. "The epidemiology and pathogenesis of coronavirus disease (COVID-19) outbreak". Journal of Autoimmunity 26 (2020): 102433.

9. Chatterjee P., et al. "The 2019 novel coronavirus disease (COVID-19) pandemic: A review of the current evidence". Indian Journal of Medical Research 151.2 (2020): 147.

10. Huang C., et al. "Clinical features of patients infected with 2019 novel coronavirus in Wuhan, China”. The Lancet 395.10223 (2020): 497-506.

11. Jin YH., et al. "A rapid advice guideline for the diagnosis and treatment of 2019 novel coronavirus (2019-nCoV) infected pneumonia (standard version)". Military Medical Research 7.1 (2020): 4 .

12. https://indianexpress.com/article/explained/dexamethasone-covid-treatment-trial-explained-6465602/

13. https://www.news18.com/news/india/favipiravir-all-youneed-to-know-about-the-new-covid-19-medicine-and-its-effects-on-patients-2679929.html

14. Dhama K., et al. "Coronavirus disease 2019-COVID-19".

15. Malik YS., et al. "Emerging Coronavirus Disease (COVID-19), a pandemic public health emergency with animal linkages: Current status update" (2020).

16. Vellingiri B., et al. "COVID-19: A promising cure for the global panic”. Science of The Total Environment 4 (2020): 138277.

\section{Assets from publication with us}

- Prompt Acknowledgement after receiving the article

- Thorough Double blinded peer review

- Rapid Publication

- Issue of Publication Certificate

- High visibility of your Published work

Website: www.actascientific.com/

Submit Article: www.actascientific.com/submission.php

Email us: editor@actascientific.com

Contact us: +919182824667 